\title{
Analysis on the Influencing Factors of the Green Supply Chain Performance of Fresh Agricultural Products under the Cloud Logistics Model
}

\author{
Yue Li $\mathbf{i}^{\text {a, * }}$, Xu Liu \\ School of Economics and Management, Shandong Huayu University of Technology, Dezhou, \\ 253034, China \\ a357933242@qq.com, b358882134@qq.com \\ *Corresponding author: 357933242@qq.com
}

Keywords: cloud logistics, fresh agricultural products, green supply chain, influencing factors of performance

Abstract: The development of green supply chain of fresh agricultural products under the cloud logistics model is the demand of the times. This paper constructs four primary evaluation indicators and 19 secondary evaluation indicators. AHP is used to analyze the factors affecting the performance of the supply chain of fresh agricultural products under the cloud logistics model. Finally, the degree of influence of each influencing factor was determined. The analysis results provide a theoretical reference for the steady development of the green supply chain of fresh agricultural products under the cloud logistics model.

\section{Introduction}

Fresh agricultural products are closely related to people's lives and are indispensable items in people's lives. However, the characteristics of the storage and insurance of fresh agricultural products determine the complexity and timeliness of the supply chain. Relying on the cloud logistics model to develop the green supply chain of fresh agricultural products is of great significance and is the only way to adapt to social development. It is of great significance to analyze the influencing factors of the green supply chain performance of fresh agricultural products under cloud logistics as the key research to promote the development and stability of the green supply chain of fresh agricultural products under the cloud logistics model. This paper analyzes the factors influencing the performance of the green supply chain of fresh agricultural products under the cloud logistics model using the AHP model, and analyzes the importance of each factor by determining the weight of each factor. Furthermore, it provides a theoretical and theoretical reference for the development of green supply chain of fresh agricultural products under the cloud logistics model.

\section{Analysis of factors affecting performance}

Through consulting relevant research literature [1-4], field investigations and expert interviews, the factors influencing the performance of the green supply chain of fresh agricultural products 
under the cloud logistics model are summarized, which are divided into 4 categories and 19 subcategories. The analysis is as follows.

(1) Information Sharing

Choosing Information Sharing as the influencing factor for the performance of the fresh agricultural products supply chain under the cloud logistics model is because the cloud logistics model requires a higher degree of information transmission and sharing. The efficient transmission and sharing of information is the basic feature of the cloud logistics model.Information sharing mainly includes five influencing factors: Information Transfer Rate, Information Technology Application Level, Enterprise Collaboration Level, Information Accuracy, and Information Timeliness.

(2) Business Flexibility

Business Flexibility is an important factor that affects the performance of the fresh agricultural products supply chain under the cloud logistics model.Among them, product diversification, supply time flexibility, inventory turnover, product quality assurance, and product circulation are important indicators of business flexibility.Therefore, Product Flexibility, Supply Time Flexibility, Inventory Turnover Rate, Product Quality, and Product Circulation are defined as secondary influencing factors under business flexibility.

(3) Environmental Benefits

Maximizing environmental benefits is an important pursuit of the green supply chain. It is also particularly important to maximize the environmental benefits of the green supply chain of fresh agricultural products under the cloud logistics model.Therefore, Environmental Benefits are selected as the influencing factors to evaluate the performance of the green supply chain of fresh agricultural products under the cloud logistics model, which mainly includes the Generation Rate of Transportation Waste, Resource Utilization Rate, Recovery Rate of Waste Products, Utilization Rate of Recyclable Materials and Resource Saving Rate.

(4) Social Benefits

The construction of the green supply chain model of fresh agricultural products under the cloud logistics model is to better comply with social and economic development, and the Social Benefits is the key influencing factors for the performance of the green supply chain of fresh agricultural products under the cloud logistics model. It mainly includes four aspects: Corporate Visibility, Corporate Green Culture, Employee Green Awareness, and Product Quality Assurance.

\section{Analysis of AHP-based performance influencing factors}

\subsection{Weight calculation of influencing factors}

With reference to relevant evaluation research literature and comparison of multiple evaluation analysis methods, this article determines the use of AHP analysis methods for analysis with the aid of yaahp software.During the research, field investigations and expert interviews were conducted on the fresh agricultural products industry in Northwestern Shandong Province. The research objects are mainly middle and high-level management personnel and scientific researchers in the industry.According to the scoring situation, the weight of each influencing factor is output through the yaahp software, and then the importance of the influencing factor is determined.Based on the analysis of the 4 major categories and 19 sub-categories of influencing factors determined by the analysis of influencing factors, the performance influencing factors structure model is constructed as shown in Figure 1. 


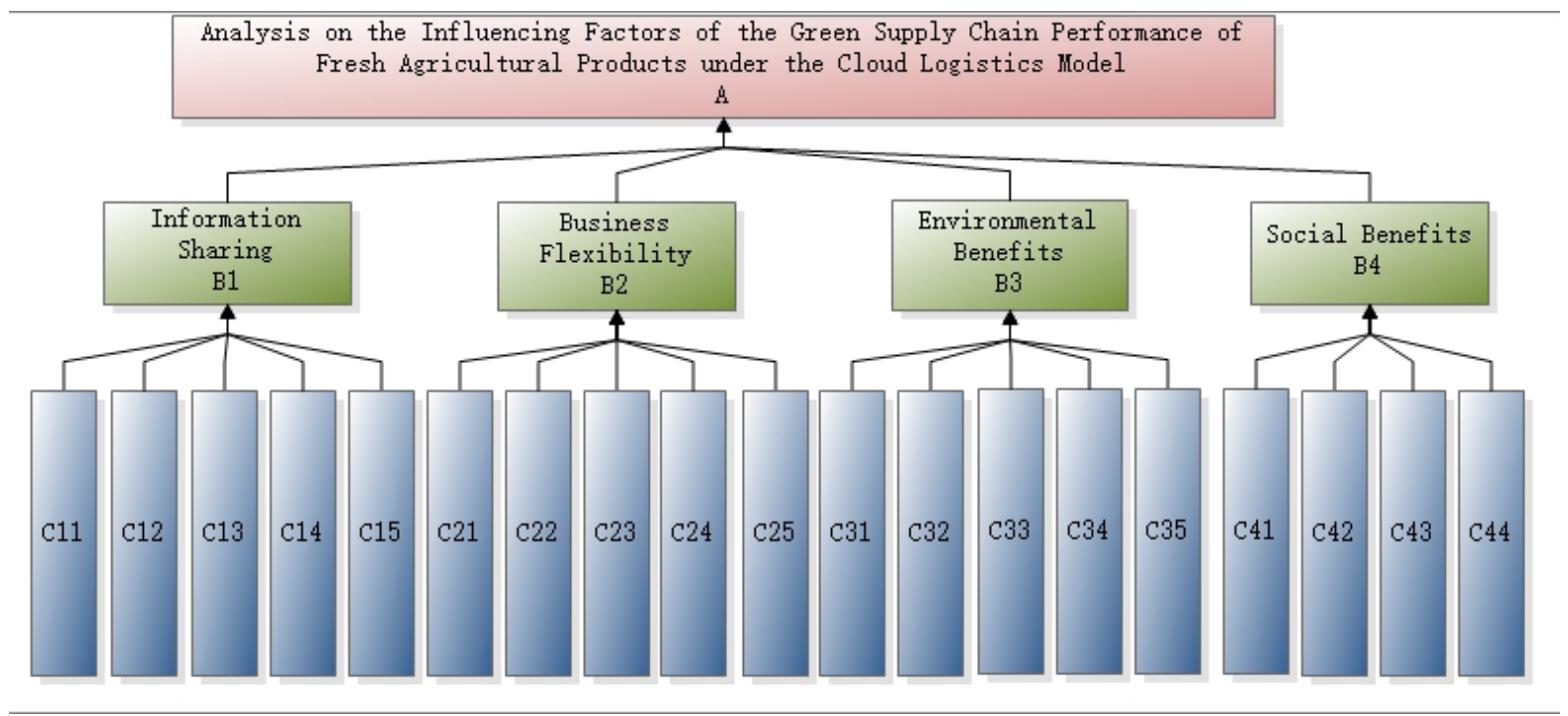

Figure. 1 Influencing factor structure model

(1) Judgment matrix and weights (B-A)

Table 1 Judgment matrix and weights (B-A)

\begin{tabular}{ccccccc}
\hline A & B1 & B2 & B3 & B4 & Wi & C.R. \\
\hline B1 & 1 & 2 & $1 / 3$ & 2 & 0.2398 & \\
B2 & $1 / 2$ & 1 & $1 / 2$ & 1 & 0.1578 & 0.0439 \\
B3 & $1 / 3$ & 2 & 1 & 3 & 0.4597 & \\
B4 & $1 / 2$ & 1 & $1 / 3$ & 1 & 0.1426 & \\
\hline
\end{tabular}

(2) Judgment matrix and weights (C-B)

Table 2 Judgment matrix and weights (C-B1)

\begin{tabular}{ccccccccc}
\hline B1 & C11 & C12 & C13 & C14 & C15 & Wi & Total Wi & C.R. \\
\hline C11 & 1 & $1 / 2$ & $1 / 4$ & $1 / 3$ & $1 / 3$ & 0.0752 & 0.0180 & \\
C12 & 2 & 1 & $1 / 2$ & $1 / 2$ & $1 / 2$ & 0.1341 & 0.0322 & \\
C13 & 4 & 2 & 1 & $1 / 2$ & $1 / 2$ & 0.2033 & 0.0488 & 0.0406 \\
C14 & 3 & 2 & 2 & 1 & 1 & 0.2532 & 0.0607 & \\
C15 & 3 & 2 & 3 & 1 & 1 & 0.3341 & 0.0801 & \\
\hline
\end{tabular}

Table 3 Judgment matrix and weights (C-B2)

\begin{tabular}{ccccccccc}
\hline B2 & C21 & C22 & C23 & C24 & C25 & Wi & Total Wi & C.R. \\
\hline C21 & 1 & 1 & $1 / 2$ & $1 / 3$ & $1 / 4$ & 0.0960 & 0.0152 & \\
C22 & 1 & 1 & 2 & $1 / 2$ & 1 & 0.1813 & 0.0286 & \\
C23 & 2 & $1 / 2$ & 1 & $1 / 2$ & $1 / 3$ & 0.1267 & 0.0200 & 0.0513 \\
C24 & 3 & 2 & 2 & 1 & 1 & 0.2980 & 0.0470 & \\
C25 & 4 & 1 & 3 & 1 & 1 & 0.2980 & 0.0470 & \\
\hline
\end{tabular}


Table 4 Judgment matrix and weights (C-B3)

\begin{tabular}{ccccccccc}
\hline B3 & C31 & C32 & C33 & C34 & C35 & Wi & Total Wi & C.R. \\
\hline C31 & 1 & 2 & 2 & 3 & 1 & 0.3112 & 0.1431 & \\
C32 & $1 / 2$ & 1 & 2 & $1 / 2$ & $1 / 2$ & 0.1435 & 0.0660 & \\
C33 & $1 / 2$ & $1 / 2$ & 1 & 1 & 1 & 0.1435 & 0.0660 & 0.0671 \\
C34 & $1 / 3$ & 2 & 1 & 1 & $1 / 2$ & 0.1520 & 0.0699 & \\
C35 & 1 & 2 & 1 & 2 & 1 & 0.2498 & 0.1149 & \\
\hline
\end{tabular}

Table 5 Judgment matrix and weights (C-B4)

\begin{tabular}{cccccccc}
\hline B4 & C41 & C42 & C43 & C44 & Wi & Total Wi & C.R. \\
\hline C41 & 1 & $1 / 2$ & $1 / 4$ & $1 / 3$ & 0.1004 & 0.0143 & \\
C42 & 2 & 1 & 1 & $1 / 2$ & 0.2221 & 0.0317 & 0.0361 \\
C43 & 4 & 1 & 1 & $1 / 2$ & 0.2641 & 0.0377 & \\
C44 & 3 & 2 & 2 & 1 & 0.4134 & 0.0590 & \\
\hline
\end{tabular}

\subsection{Results analysis}

Through the weight analysis of AHP calculation of various influencing factors, it is concluded that Environmental Benefits are the key factors affecting the performance of the green supply chain under the cloud logistics model, followed by Information Sharing, Business Flexibility, and finally Social Benefits.

(1) Information Sharing: According to Table2, the weight calculation results of the five factors show: Information Timeliness > Information Accuracy $>$ Enterprise Collaboration Level > Information Technology Application Level > Information Transfer Rate. Explain that Information Timeliness has the greatest impact on the performance of the green supply chain of fresh agricultural products under the cloud logistics model. Therefore, during the construction and management of the green supply chain of fresh agricultural products under the cloud logistics model, attention should be paid to the timeliness of information sharing and the establishment of rapid response information interaction Platform to improve the performance of the green supply chain of fresh agricultural products.

(2) Business Flexibility: According to Table3, the weight calculation results of the five factors show: Product Circulation = Product Quality $>$ Supply Time Flexibility $>$ Inventory Turnover Rate $>$ Product Flexibility. In terms of business flexibility, Product Circulation and Product Quality have the greatest impact on the performance of the green supply chain of fresh agricultural products under the cloud logistics model. While realizing the green supply chain of fresh agricultural products under the cloud logistics model, focusing on product circulation and product quality is more conducive to ensuring supply Chain performance improvement.

(3) Environmental Benefits: According to Table3, the weight calculation results of the five factors show: Generation Rate of Transportation Wastes > Resource Saving Rate > Utilization Rate of Recyclable Material > Recovery Rate of Waste Products= Resource Utilization Rate.It shows that the environmental impact on the performance of the green supply chain of fresh agricultural products under the cloud logistics model has the greatest impact on the generation of waste during transportation. It is necessary to choose the appropriate transportation means, choose the appropriate transportation route, and adopt a reasonable and scientific method of freshness preservation. To avoid excessive waste during transportation.

(4) Social Benefits: The impact of Social Benefits on the benefits of the green supply chain is the smallest of the four major types of influencing factors. As can be seen from Table 5, the weight 
calculation results of the four major types of influencing factors show that: Product Quality Assurance > Employee Green Awareness > Corporate Green Culture > Corporate Visibility. Explain that product quality assurance is the most important for supply chain performance. To achieve green supply chain construction and management of fresh agricultural products under the cloud logistics model, product quality must be guaranteed.

\section{Conclusion}

Based on the characteristics of the green supply chain of fresh agricultural products under the cloud logistics model, four categories and 19 categories of factors that affect the performance of the supply chain are analyzed. Using the AHP method, the weight of each influencing factor was calculated with the help of yaahp software. Among all the influencing factors, Information Timeliness has the highest weight, indicating that the timeliness and effectiveness of information sharing should be ensured in the process of green supply chain management, which is conducive to improving supply chain performance.

\section{Acknowledgements}

The authors gratefully acknowledge the financial support from:2018 Shandong Province University Research Program Project (Humanities and Social Sciences) "Green Supply Chain

Innovation and Practice of Fresh Agricultural Products in Northwestern Shandong under Cloud Logistics Model "(J18RA098); 2019 Shandong Social Science Planning and Research Project "Research on Green Supply Chain Innovation and Practice Based on 'Cloud Logistics' Model "(19CPYJ11); 2020 funded project of Institute of Technology Smart Logistics and Supply Chain Research Center in Shandong Huayu University of Technology.

\section{References}

[1] SUI Bo-wen. Performance Appraisal of Cross-border Agro-food Supply Chain Alliance: An Empirical Analysis between Guangxi Province and ASEAN [J]. Journal of Beijing Jiaotong University (Social Sciences Edition), 2017,16 (03): 129-136.

[2] HU Fei. Evaluation Method and Application of Green Supply Chain Performance of Henan Agricultural Products [D]. Taiyuan University of Technology, 2017.

[3] WANG Gang, WANG Zhen. Research on Risk Evaluation of Agricultural Product Supply Chain Based on "Cloud Logistics" Model [J]. China Market, 2018 (15): 178-179.

[4] CHEN Xiao-hua, YAN Xue-qing. Distribution Patter of the Fresh Agricultural Products Based on Green Supply Chain Management, Logistics Sci-Tech, 2015, 38 (05): 95-98.

[5] LI Hong-xia, XIE Rui-rui, Analysis of Factors Affecting Emergency Capability of Miners Based on AHP [J]. Coal Technology, 2018, 37 (07): 348-350.

[6] LI Yuan-yuan, LIU Li-shuai. Research on Risk Evaluation of Agriculture Product Supply Chain Based on ANP-Fuzzy Model [J]. Mathematics in Practice and Theory, 2017, 47 (13): 24-32. 